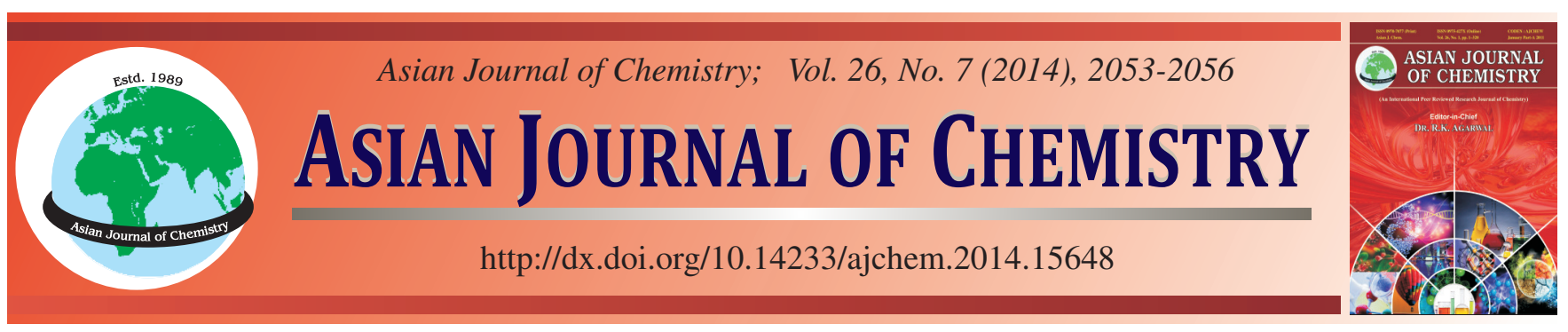

\title{
Synthesis and Characterization of Triphenylamine Appended Porphyrins and their Intramolecular Energy Transfer
}

\author{
M. BAI, Q. MA, R. Song and F. MENG
}

Marine College, Shandong University, Weihai 264209, P.R. China

*Corresponding author: Tel./Fax: + 86631 5688303; E-mail: ming_bai@sdu.edu.cn

A series of 5,10,15-triphenyl-20-(triphenylamino)porphyrinato zinc(II) (ZnTPP(TPA) (1), 5-phenyl-10,15,20-tris(triphenylamino)porphyrinato zinc(II) (ZnTPP(TPA) 3 (2) and 5,10,15,20-tris(triphenylamino)porphyrinato zinc(II) (ZnTPP(TPA) 4 (3) were synthesized using 4-(N,N-diphenylamino)benzaldehyde, benzaldehyde and pyrrole as starting materials. All porphyrins were characterized with various spectroscopic methods, MALDI-TOF mass, UV-vis, ${ }^{1} \mathrm{H}$ NMR and 2D COSY spectroscopy. The structure of 5,10,15-triphenyl20-(triphenylamino)porphyrin $\left[\mathrm{H}_{2} \mathrm{TPP}(\mathrm{TPA})\right]$ was also established by X-ray diffraction analyses. The absorption and emission spectra indicate that there are strong interactions between zinc porphyrin core and triarylamine at ground states. Excited energy transfer from triphenylamine to porphyrin was proved by the fluorescence spectra.

Keywords: Triphenylamine, Porphyrin, Energy transfer.

ᄂ - - - - - - - - - - - - - - - - - - - - - - - -

\section{INTRODUCTION}

Porphyrins are versatile functional molecules for their unique photophysical and electrochemical properties which also can be expediently controlled by modified with proper functional groups at the meso and/or $\beta$ positions on the macrocycle $^{1,2}$. Triphenylamine (TPA)-originated derivatives are widely investigated as optoelectronic materials in different applications, such as organic light-emitting diode ${ }^{3-5}$, dye-sensitized solar cells (DSSC) $)^{3,6-9}$ and electrochromic polymer ${ }^{3,10}$. Recently, hybridizations of porphyrin and triphenylamine have attracted much attention. Porphyrins that have a $\pi$-conjugated triphenylamine at the meso-position opposite the anchoring group have been synthesized and its application as sensitizer in dye-sensitized solar cells resulted in extremely high power conversion efficiencies ${ }^{11}$. The compound with hexyl chains on the diarylamino-substituent, giving an overall power conversion efficiency of $6.6 \%$. The compound zinc(II) 5,15-bis(4(diphenyl-amino)phenyl)-10-(3,4,5-trimethoxyphenyl)-20-(4carboxylphenylethynyl)porphyrin is synthesized and its overall power conversion efficiency of the dye-sensitized solar cells is as high as $5.45 \%$. Donor-bridge-acceptor conjugates, 5,10,15,20-tetrakis [4-(N,N-diphenylaminostyryl)phenyl] porphyrin and $(5,10,15,20$-tetrakis $[4-(\mathrm{N}, \mathrm{N}$-diphenylaminobenzoate)phenyl]porphyrin, were used for synthesizing platinum nanocomposite for photocatalyzing hydrogen evolution $^{13}$. Thin polymer films of 5-(2-phenoxyacetamide)or 5-(2,5-phenylenebis(oxy)diacetamide)-10,15,20-tris(triphenylamino)porphyrinato zinc(II), which deposited by multicyclic potentiodynamic electropolymerization, could be used as sensor to determine alkaloids, such as, nicotine, cotinine and myosmine at the concentration level of $0.1 \mathrm{mM}$ with high sensitivity and selectivity ${ }^{14}$.

Due to these magnificent properties of porphyrin-triphenylamine compounds as mentioned above, the interaction of triphenylamine group with porphyrinato zinc attracted much attention. Spectral and electrochemical investigation of porphyrin-triphenylamine dendrimers has been reported. Because of the presence of antenna effect of the triphenylamine dendrons in these dendrimers, the fluorescence quantum yields of prphyrin were strongly enhanced when more triphenylamine moieties were selectively excited ${ }^{15}$. The electronic interaction between porphyrin and triphenylamine was also investigated through a series of Por-triphenylamine conjugate ${ }^{16}$. In this work, we synthesized a mono-, tri- and tetra-triphenylamine substituted porphyrinato zinc complexes. The photoinduced intramolecular energy transfer from triphenylamine to the zinc porphyrin core was investigated by absorption and emission spectra. The difference on the properties between these compounds, which caused by the different number of triphenylamine groups, are discussed. 


\section{EXPERIMENTAL}

All of the other chemicals and solvents such as 4-(N,Ndiphenylamino)benzaldehyde, benzaldehyde and $\mathrm{Zn}(\mathrm{OAc})_{2} \cdot 2 \mathrm{H}_{2} \mathrm{O}$ were bought from commercial source and used as received. Column chromatography was carried out on a silica gel column (Qingdao Haiyang, 200-300 mesh) with the indicated eluents.

Detection method: ${ }^{1} \mathrm{H}$ NMR spectra were recorded on a Bruker DPX 400 spectrometer $\left({ }^{1} \mathrm{H}: 400 \mathrm{MHz}\right)$ in $\mathrm{CDCl}_{3}$ solutions unless otherwise stated. Spectra were referenced internally using the residual solvent resonances ( $\delta=7.26$ for ${ }^{1} \mathrm{H}$ NMR) relative to $\mathrm{SiMe}_{4}(\delta=0 \mathrm{ppm})$. Electronic absorption spectra were recorded on a Hitachi U-4100 spectrophotometer. The fluorescence spectra were recorded on Perkin Elmer LS-45. MALDI-TOF mass spectra were taken on a Bruker BIFLEX III ultrahigh resolution Fourier transformation cyclotron resonance (FT-ICR) mass spectrometer with R-cyano-4hydroxycinnamic acid as a matrix. Single crystals of all the complexes for X-ray diffraction analysis with suitable dimensions were mounted on the glass rod and the crystal data were collected on an Oxford Diffraction Gemini E diffractometer.

Synthesis of triphenyl-substituted porphyrinato zinc(II) complexes (1-3): Added in succession 4-(N,N-diphenylamino)benzaldehyde $2.73 \mathrm{~g}(10 \mathrm{mmol})$, benzaldehyde $1.06 \mathrm{~g}$ $(10 \mathrm{nmol})$ and pyrrole $1.32 \mathrm{~g}(20 \mathrm{mmol})$ to $30 \mathrm{~mL}$ of refluxing propionic acid. Reflux the mixture for $3 \mathrm{~h}$ and then cool it to room temperature. Then the reaction mixture was poured into $100 \mathrm{~mL}$ methanol. After filtration, the solid product was purified by silica-gel column chromatography using $\mathrm{CH}_{2} \mathrm{Cl}_{2} /$ hexane (from 1/10 to 5/10) as eluent. The metal free porphyrins and $\mathrm{Zn}(\mathrm{OAc})_{2} \cdot 2 \mathrm{H}_{2} \mathrm{O}$ were dissolved in $50 \mathrm{~mL} \mathrm{DMF}$ and refluxed for $1 \mathrm{~h}$. After the solvent was removed in vacuo, the product was purified by silica-gel column chromatography using $\mathrm{CH}_{2} \mathrm{Cl}_{2}$ as eluent.

5,10,15-Triphenyl-20-(triphenylamino)porphyrinato zinc(II) [ZnTPP(TPA)] (1): Yield: $219.78 \mathrm{mg}(5.2 \%) .{ }^{1} \mathrm{H}$ NMR (400 MHz, $\mathrm{CDCl}_{3}$ ): $\delta 9.10(\mathrm{~d}, 2 \mathrm{H}, J=4.4 \mathrm{~Hz}, \mathrm{ArH})$, 8.98 (d, 2H, $J=4.8 \mathrm{~Hz}, \mathrm{ArH}), 8.95$ (s, 4H, ArH), 8.23 (br s, $6 \mathrm{H}, \mathrm{ArH}), 8.08$ (d, 2H, $J=8.4 \mathrm{~Hz}, \mathrm{ArH}), 7.77$ (br s, 9H, ArH), 7.45 (d, 2H, $J=8.4 \mathrm{~Hz}, \mathrm{ArH}), 7.41-7.42$ (m, 8H, ArH), 7.14 (br s, 2H, ArH). MS (MALDI-TOF) $m / z: 843.23[\mathrm{M}]^{+} 843.99$.
5-Phenyl-10,15,20-tris(triphenylamino)porphyrinato zinc(II) [ZnTPP(TPA) ${ }_{3}$ ] (2): Yield: $283.37 \mathrm{mg}(4.8 \%) . \delta \mathrm{H}$ $\left(400 \mathrm{MHz}, \mathrm{CDCl}_{3}\right): 9.13$ (s, 4H, ArH), 9.10 (d, 2H, $J=4.8$ $\mathrm{Hz}, \mathrm{ArH}), 8.98$ (d, 2H, $J=4.4 \mathrm{~Hz}, \mathrm{ArH}), 8.24$ (d, 2H, $J=6.4$ $\mathrm{Hz}, \mathrm{ArH}), 8.09$ (d, 6H, J = 8.0 Hz, ArH), 7.76-7.80 (m, 3H, ArH), 7.47 (d, 6H, J=8.4 Hz, ArH), 7.42-7.43 (m, 24H, ArH), 7.15 (br s, 6H, ArH). MS (MALDI-TOF) $\mathrm{m} / z: 1010.31[\mathrm{M}]^{+}$ 1010.34 .

$\mathbf{5 , 1 0 , 1 5 , 2 0 - T r i s ( t r i p h e n y l a m i n o ) p o r p h y r i n a t o ~ z i n c ( I I ) ~}$ [ZnTPP(TPA) $)_{4}$ (3): Yield: $107.85 \mathrm{mg}(1.6 \%) . \delta \mathrm{H}(400 \mathrm{MHz}$, $\mathrm{CDCl}_{3}$ ): 9.12 (s, 2H, ArH), 8.09 (d, 2H, $\left.J=8.0 \mathrm{~Hz}, \mathrm{ArH}\right), 7.47$ (d, 2H, $J=8.0 \mathrm{~Hz}, \mathrm{ArH}), 7.42-7.43(\mathrm{~m}, 8 \mathrm{H}, \mathrm{ArH}), 7.15(\mathrm{t}, 2 \mathrm{H}$, $J=4.0 \mathrm{~Hz}$, ArH). MS (MALDI-TOF) $\mathrm{m} / z: 1344.46\left[\mathrm{M}^{+}\right.$ 1345.00

\section{RESULTS AND DISCUSSION}

The synthetic procedures of these compounds are shown in Scheme-I. The metal free porphyrins were synthesized using 4-(N,N-diphenylamino)benzaldehyde, benzaldehyde and pyrrole as starting materials. After metalized with $\mathrm{Zn}(\mathrm{OAc})_{2} \cdot 2 \mathrm{H}_{2} \mathrm{O}$ in $\mathrm{CH}_{2} \mathrm{Cl}_{2}$ and $\mathrm{CH}_{3} \mathrm{OH}$, the porphyrinato zinc compolexes, ZnTPP(TPA) (1), ZnTPP(TPA) $)_{3}$ (2) and ZnTPP(TPA $)_{4}$ (3) were prepared and separated successfully.

These compounds were characterized by MALDI-TOF mass, ${ }^{1} \mathrm{H}$ NMR, UV-vis spectroscopy. The MALDI-TOF mass spectra of these compounds clearly showed intense signals for the molecular ion $\left(\mathrm{M}^{+}\right)$. ${ }^{1} \mathrm{H}$ NMR spectra of compound $\mathrm{ZnTPP}(\mathrm{TPA}), \mathrm{ZnTPP}(\mathrm{TPA})_{3}$ and $\mathrm{ZnTPP}(\mathrm{TPA})_{4}$ were recorded in $\mathrm{CDCl}_{3}$.

Single crystals of $\mathrm{H}_{2}$ TPP(TPA) suitable for X-ray diffraction analysis were obtained by slow diffusion of $\mathrm{MeOH}$ into the corresponding $\mathrm{CHCl}_{3}$ solution ${ }^{17}$. Compound $\mathrm{H}_{2} \mathrm{TPP}(\mathrm{TPA})$ crystallizes in the monoclinic system with $\mathrm{P} 2 / \mathrm{c}$ space group. As shown in Fig.1, the four indole rings form the planar core with the average dihedral angel of $2.16^{\circ}$ between the pyrrole and porphin core. The average dihedral angle between the three benzene groups on the meso-position and porphin core is $80.07^{\circ}$ due to the steric effect. Strong electronic interaction requires efficient $\pi$-orbital overlap and this can be examined by the dihedral angles between the aromatic rings. The dihedral angle between the meso-position benzene ring of triphenylamine and porphin core is $53.35^{\circ}$, which is much smaller than

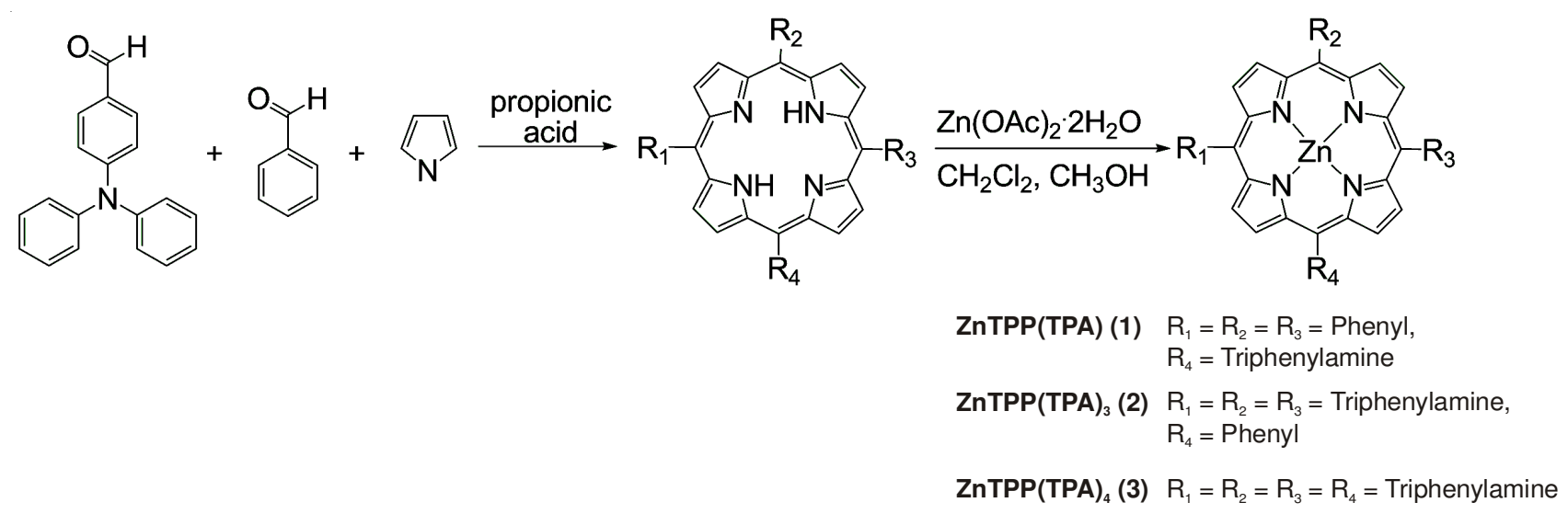

Scheme-I: Synthesis of porphyrins ZnTPP(TPA) (1), ZnTPP(TPA $)_{3}(\mathbf{2})$ and ZnTPP(TPA $)_{4}(\mathbf{3})$ 
TABLE-1

ELECTRONIC ABSORPTION DATA FOR ZnTPP AND COMPOUNDS 1-3 IN TOLUENE

\begin{tabular}{cccccc}
\hline Compound & \multicolumn{1}{c}{$\lambda_{\max }(\mathrm{nm})\left(\log \varepsilon / \mathrm{dm}^{3} \mathrm{~mol}^{-1} \mathrm{~cm}^{-1}\right)$} & $\Phi_{\mathrm{f}}(\%)^{\mathrm{a}}$ \\
\hline ZnTPP & & $422(5.81)$ & $549(4.46)$ & $588(3.65)$ & 3.3 \\
ZnTPP(TPA) (1) & $302(4.69)$ & $425(5.55)$ & $550(4.39)$ & $591(3.85)$ & 3.6 \\
ZnTPP(TPA) $)_{3}(\mathbf{2})$ & $306(4.84)$ & $436(5.43)$ & $554(4.32)$ & $597(4.02)$ & 5.8 \\
ZnTPP(TPA) $)_{4}(3)$ & $306(5.02)$ & $440(5.49)$ & $556(4.38)$ & $598(4.18)$ & 6.2 \\
\hline
\end{tabular}

Quantum yield of $\mathrm{ZnTPP}$ in toluene $\left(\Phi_{\mathrm{f}}=3.3 \%\right)$ as standard; TPA = Triphenylamine.

that between the benzene rings and porphin ring. The dihedral angles of neighboring benzene rings of triphenylamine are $69.78,69.78$ and $74.72^{\circ}$. It is noteworthy that the neighboring molecules are connected by the intermolecular $\pi-\pi$ interaction between the triphenylamine and the porphyrin core (Fig. 2).

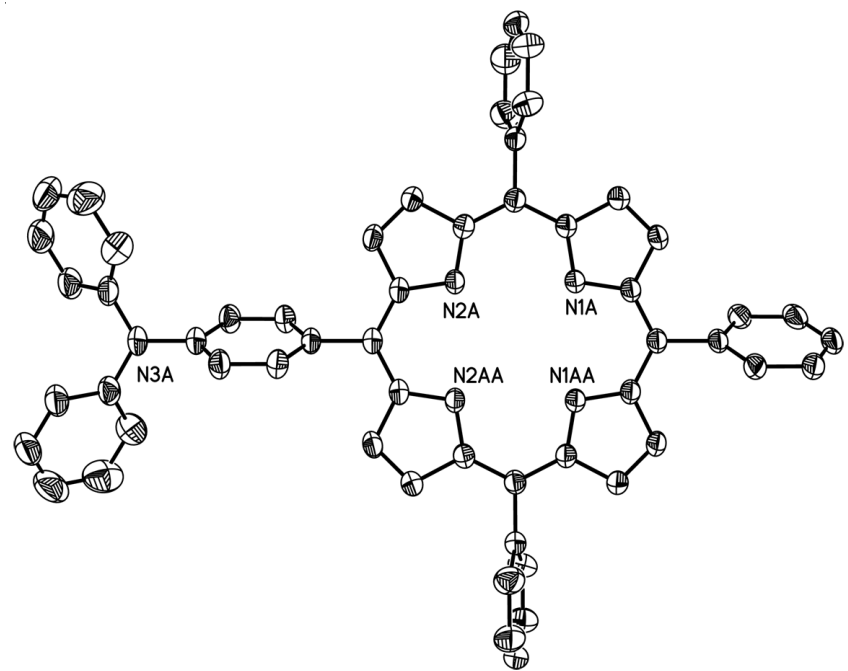

Fig. 1. ORTEP drawing of compound $\mathrm{H}_{2} \mathrm{TPP}(\mathrm{TPA})$ ( $30 \%$ probability thermal ellipsoids). Hydrogen atoms and the pyridine molecule are omitted for clarity
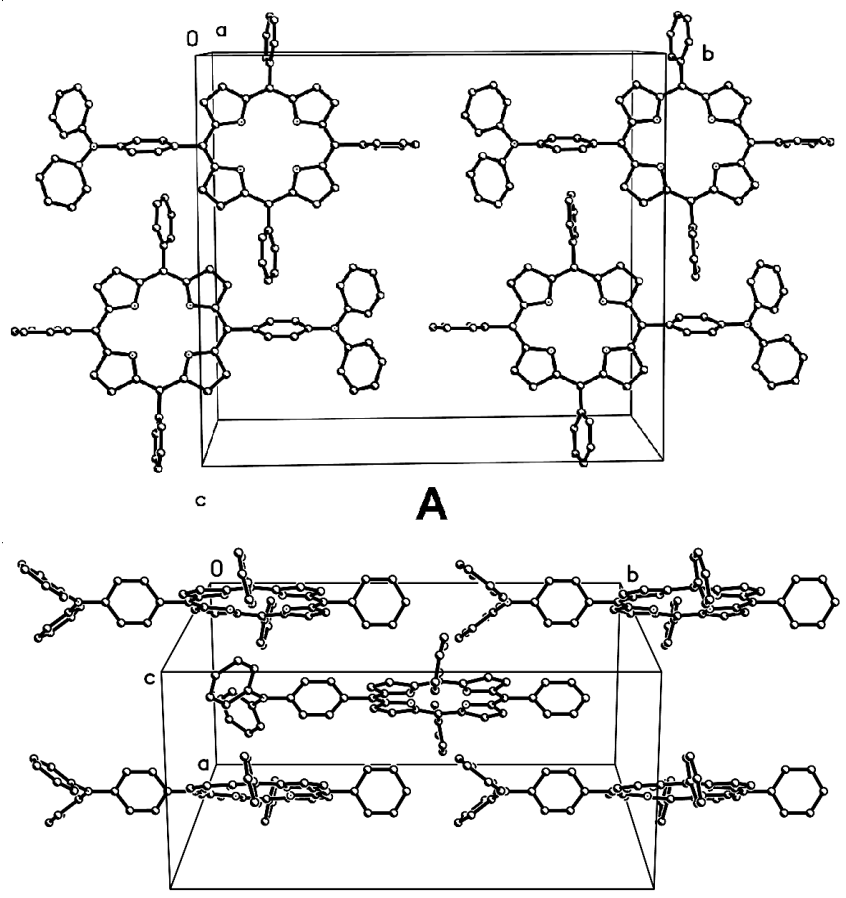

B

Fig. 2. Crystal-packing diagrams for compound $\mathrm{H}_{2} \mathrm{TPP}(\mathrm{TPA})(\mathrm{A})$ and (B). Hydrogen atoms are omitted for clarity
Absorption spectra of all compounds were recorded in toluene and the data are given in Table-1. The spectra shown in Fig. 3 indicate that large change on the shape has been induced by the introduction of triphenylamine groups on the porphyrin ring. For comparison purpose, the absorption spectra of triphenylamine in the same solvent are also shown in Fig. 4. Along with the increase on the number of triphenylamine groups connected, the Soret band of porphyrin red shifted gradually from about 420 for ZnTPP to $440 \mathrm{~nm}$ for ZnTPP(TPA $)_{4}$. Similar red shifts are also observed for the $\mathrm{Q}$ bands in the range of 550-600 $\mathrm{nm}$. This indicates that presence of strong ground state interactions between the triphenylamine groups and porphyrin. The broad absorption of triphenylamine groups of these compounds in the range of 280-340 nm does not shown distinctive change in comparison with that of pure triphenylamine.

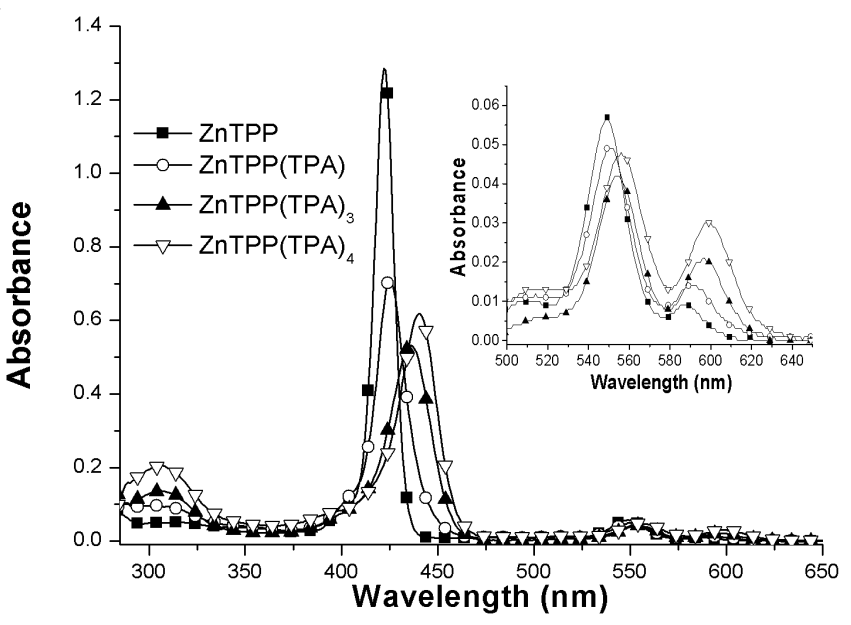

Fig. 3. UV-visible spectra of compounds ZnTPP, 1-3 in toluene. The concentrations were fixed at $2 \times 10^{-6} \mathrm{M}$

The fluorescence spectra of triphenylamine in toluene show a broad emission band in the range of 340-440 $\mathrm{nm}$ with the maximum peak at about $380 \mathrm{~nm}$ (Fig. 4). But this emission is missing in the fluorescence spectra of $\mathrm{ZnTPP}(\mathrm{TPA})$, $\mathrm{ZnTPP}(\mathrm{TPA})_{3}$ and $\mathrm{ZnTPP}(\mathrm{TPA})_{4}$ when triphenylamine was selectively excited at $300 \mathrm{~nm}$ (Fig. 5). This means that the emission of triphenylamine was efficiently quenched by porphyrin ring. Meanwhile, the emission of porphyrin at about $620 \mathrm{~nm}$ was observed with a large intensity. Because the absorption of porphyrin at the excitation wavelength $(300 \mathrm{~nm})$ is extremely small, the direct excitation of ZnTPP at $300 \mathrm{~nm}$ did not induce strong emission at $620 \mathrm{~nm}$ as shown in Fig 5. The strong emission of ZnTPP(TPA), ZnTPP(TPA) ${ }_{3}$ and $\mathrm{ZnTPP}(\mathrm{TPA})_{4}$ at $620 \mathrm{~nm}$ when triphenylamine were excited are therefore can be attributed to the efficient intramolecular 
energy transfer from triphenylamine to porphyrin. Because the triphenylamine's emissions at $380 \mathrm{~nm}$ were completely quenched, the energy transfer efficiencies are therefore estimated to be $100 \%$. The increased fluorescence quantum yields of ZnTPP(TPA), ZnTPP(TPA $)_{3}$ and ZnTPP(TPA $)_{4}$ in Table-1 suggest again the efficient antenna effects of the triphenylamine groups in these compounds.

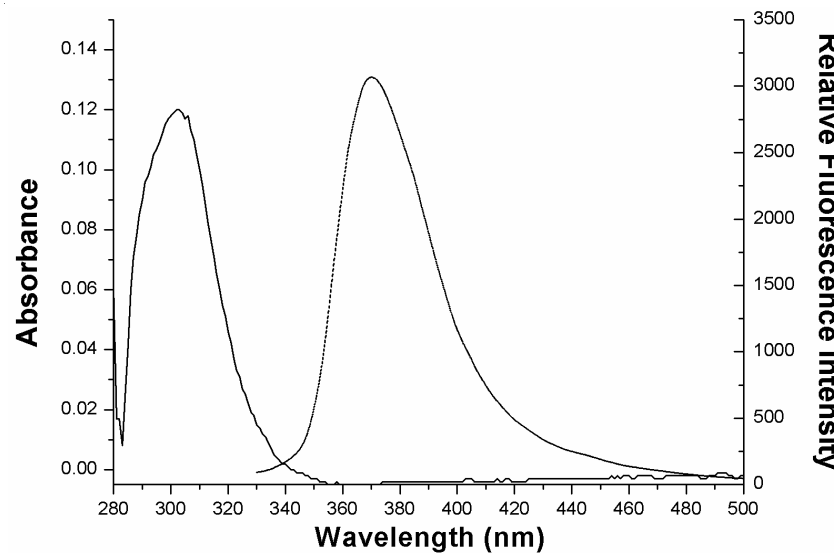

Fig. 4. UV-Vis (full) and the fluorescence (dotted) spectra of compound triphenylamine in toluene

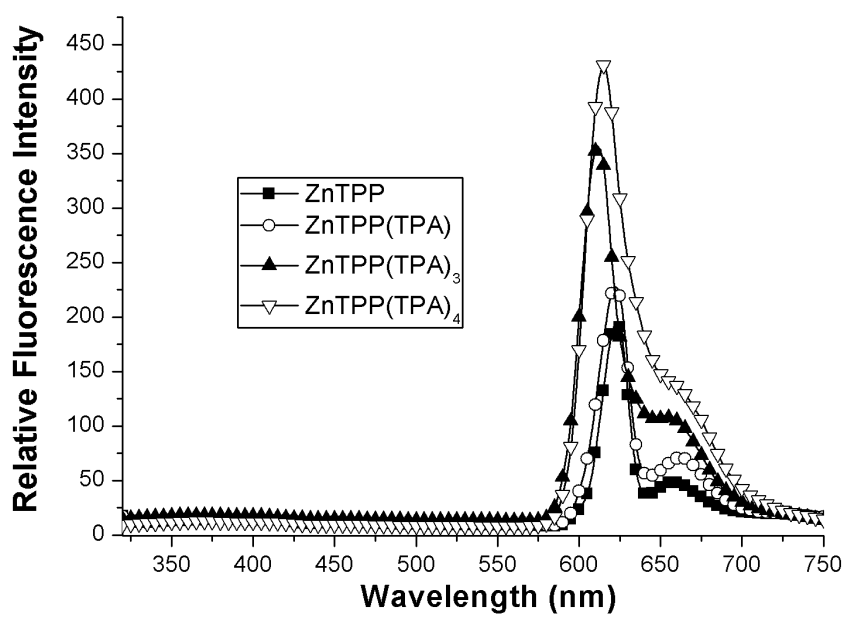

Fig. 5. Fluorescence spectra of compounds ZnTPP, 1-3 were excited at $310 \mathrm{~nm}$ in toluene. The concentrations of porphyrins were fixed at $2 \times 10^{-6} \mathrm{M}$

\section{Conclusion}

A series of triphenylamine substituted porphyrinato zinc(II) complexes have been prepared. All porphyrins were characterized with spectroscopic methods. In the emission spectroscopy study, the efficient intramolecular energy transfer from triphenylamine to porphyrin is found in 1-3. Triphenylamine absorb the UV light and then transfer the energy to the porphyrin core. Fluorescence in the visible region subsequently is emitted from porphyrin. The fluorescence quantum yields were enhanced when more triphenylamine moieties were linked. The results of this research revealed that triphenylamine and porphyrin hybrid compounds are ideal models for the mimic of light harvesting arrays in natural photosynthesis systems. Further studies on this kind of compounds will be helpful for us on deeper understanding the natural light harvesting process and developing new artificial photosynthetic systems.

\section{ACKNOWLEDGEMENTS}

Financial support from the Natural Science Foundation of China (Grant No. 21001069) and the Independent Innovation Foundation of Shandong University, IIFSDU.

\section{REFERENCES}

1. K.M. Kadish, in eds.: K.M. Kadish, K.M. Smith and R. Guilard, The Porphyrin Handbook, Academic Press, San Diego, CA, vol. 1, pp. 1-44 (2000).

2. K.M. Kadish, E.V. Caemelbecke and G. Royal, in eds.: K.M. Kadish, K.M. Smith and R. Guilard, The Porphyrin Handbook, Academic Press, San Diego, CA, vol. 8, pp. 3-114 (2000)

3. A. Iwana and D. Sek, Prog. Polym. Sci., 36, 1277 (2011).

4. Y. Tao, C. Yang and J. Qin, Chem. Soc. Rev., 40, 2943 (2011).

5. A. Chaskar, H.F. Chen and K.T. Wong, Adv. Mater., 23, 3876 (2011).

6. J. He, F. Guo, X. Li, W. Wu, J. Yang and J. Hua, Chem. Eur. J., 18, 7903 (2012).

7. K. Pei, Y. Wu, W. Wu, Q. Zhang, B. Chen, H. Tian and W. Zhu, Chem. Eur. J., 18, 8190 (2012).

8. D.W. Chang, H.J. Lee, J.H. Kim, S.Y. Park, S.-M. Park, L. Dai and J.-B. Baek, Org. Lett., 13, 3880 (2011).

9. Y. Ooyama and Y. Harima, Eur. J. Org. Chem., 2903 (2009).

10. H.-J. Yen and G.-S. Liou, Polym. Chem., 3, 255 (2012).

11. C.-P. Hsieh, H.-P. Lu, C.-L. Chiu, C.-W. Lee, S.-H. Chuang, C.-L. Mai, W.-N. Yen, S.-J. Hsu, E.W.-G. Diau and C.-Y. Yeh, J. Mater. Chem., 20, 1127 (2010).

12. B. Liu, W. Zhu, Y. Wang, W. Wu, X. Li, B. Chen, Y.-T. Long and Y. Xie, J. Mater. Chem., 22, 7434 (2012).

13. M. Zhu, Y. Dong, Y. Du, Z. Mou, J. Liu, P. Yang and X. Wang, Chem. Eur. J., 18, 4367 (2012).

14. K. Noworyta, W. Kutner, C.A. Wijesinghe, S.G. Srour and F. D'Souza, Anal. Chem., 84, 2154 (2012).

15. C.-Y. Huang and Y.O. Su, Dalton Trans., 39, 8306 (2010).

16. C.-Y. Huang, C.-Y. Hsu, L.-Y. Yang, C.-J. Lee, T.-F. Yang, C.-C. Hsu, C.-H. Ke and Y.O. Su, Eur. J. Inorg. Chem., 1038 (2012).

17. Crystal data $\mathrm{C}_{57} \mathrm{H}_{40} \mathrm{C}_{13} \mathrm{~N}_{5}, \mathrm{M}=901.29$, monoclinic, $\mathrm{P} 2 / \mathrm{c}, \mathrm{Z}=4$, a = 10.3366(3) $\AA, \mathrm{b}=22.2075(6) \AA, \mathrm{c}=20.2667(5) \AA, \alpha=90^{\circ}, \beta=$ 91.983(2) ${ }^{\circ}, \gamma=90^{\circ}, \mathrm{U}=4649.4(2) \AA 3, \mathrm{D}_{\text {calc }}=1.288 \mathrm{~g} \mathrm{~cm}^{-3}, 15,870$ independent data were collected with graphite monochromatic $\mathrm{CuK} \alpha$ radiation $(\lambda=1.54178 \AA$ ) using the SMART and SAINT programs at 293(2) K using Oxford Diffraction Gemini E diffractometer. The structures were solved by the direct method (SHELXS-97). Anisotropic thermal parameters were used for the non-hydrogen atoms and isotropic parameters for the hydrogen atoms. Hydrogen atoms were added geometrically and refined using a riding model. The structure was refined by full-matrix least-squares (SHELXS-97) on $\mathrm{F}^{2}$ to $\mathrm{R}_{1}=0.0537, \mathrm{wR}_{2}$ $=0.1582$ for 7880 reflections with $\mathrm{I}>2 \sigma(\mathrm{I})$ respectively. CCDC 723302 contains the supplementary crystallographic data for this paper. These data can be obtained free of charge from The Cambridge Crystallographic Data Centre via http://www.ccdc.cam. ac.uk/data_request/cif. 